Reprod. Nutr. Dévelop., 1985, 25 (1 B), 251-253.

\title{
Incidence du taux des acides gras essentiels du régime sur la répartition des acides gras polyinsaturés des lipoprotéines chez le raton
}

\author{
A. NOUVELOT, Edith DEDONDER, G. SEZILLE, J. M. BOURRE $\left({ }^{*}\right)$
}

Laboratoire de Physiopathologie des Lipides, Faculté de Pharmacie, 3, rue du Dr Laguesse, 59045 Lille Cedex, France.

(*) Unité de Neurotoxicologie, INSERM U.26, Hôpital F. Widal, Paris.

Le cerveau ne synthétise pas tous les acides gras nécessaires à l'élaboration de ses membranes ; l'évaluation des résultats enzymatiques obtenus in vitro comparés aux vitesses de renouvellement a permis de montrer que le cerveau ne peut élaborer que $60 \%$ environ de ses acides gras (Bourre et al., 1978). Le cerveau a été considéré pendant longtemps comme un organe autonome indépendant des apports exogènes quant à ses besoins en acides gras non essentiels ; or, il est maintenant démontré que même pour cette catégorie d'acides gras, une origine plasmatique est évidente. A fortiori, la présence en quantité importante d'acides gras polyinsaturés des séries $n-3$ et $n-6$ dans la substance grise implique une origine sérique des acides gras insaturés soit en tant qu'acides gras essentiels en C18 (Cohen et Bernsohn, 1978 ; Dhopeshwarkar, 1971a, b ; Dhopeshwarkar et Subramaniam, 1976), soit sous forme de plus longues chaînes, déjà synthétisés dans le tissu hépatique (Sinclair, 1975 ; Sinclair et Crawford, 1972).

Sans préjuger des modes de transport à travers la barrière hématoencéphalique, nous nous sommes attachés dans un premier temps à estimer l'incidence du taux d'acide linoléique dans le régime sur les disponibilités potentielles du cerveau en acides gras polyinsaturés et par là même l'importance du métabolisme intrahépatique par le biais de la répartition des acides gras au sein des lipoprotéines sériques.

Nous avons utilisé quatre régimes différents à $10 \%$ de lipides. Les régimes sont apportés ad libitum aux mères dès l'accouplement et pendant les périodes de gestation et de lactation. Le groupe A reçoit de l'huile d'arachide, les groupes $B$ et $C$ des mélanges d'huile d'arachide et de colza Primor et le groupe $D$ reçoit de l'huile de colza Primor. Dans ces différents régimes, l'apport en $18: 2$ n-6 est comparable et les taux de $18: 3$ n-3 sont respectivement de 0,2 \%-1 \%-2 \% et $9 \%$.

Les animaux sont sacrifiés à l'âge de 15 jours et sur les prélèvements sanguins nous avons séparé deux groupes de lipoprotéines: les VLDL-LDL et les HDL. 
La grande sensibilité du tissu hépatique aux conditions nutritionnelles se traduit certes par des répartitions différentes in situ des acides gras polyinsaturés, mais également par des modifications de la nature et du taux de ces mêmes composants lipidiques au sein des lipoprotéines libérées par le sang. Globalement l'enrichissement du régime en $18: 3 \mathrm{n}-3$ se traduit par un enrichissement en homologues supérieurs de cette série et un appauvrissement en acides gras de la série $n-6$. Cette observation est particulièrement nette lorsque l'apport en $18: 3 n-3$ dépasse $2 \%$ des acides gras totaux (fig. 1 ).

Le métabolisme hépatique permet la sécrétion importante dans les phospholipides des lipoprotéines d'acides gras polyinsaturés à longues chaînes. Ces acides gras polyinsaturés semblent jouer un rôle déterminant dans la synthèse des phospholipides membranaires du cerveau. En effet des cultures de cellules fœetales d'hémisphères cérébraux de souris prélevés au $16^{\mathrm{e}}$ jour de la vie embryonnaire ont permis de montrer que seule l'addition simultanée de $22: 6 \mathrm{n}-3$ et $20: 4 \mathrm{n}-6$ dans
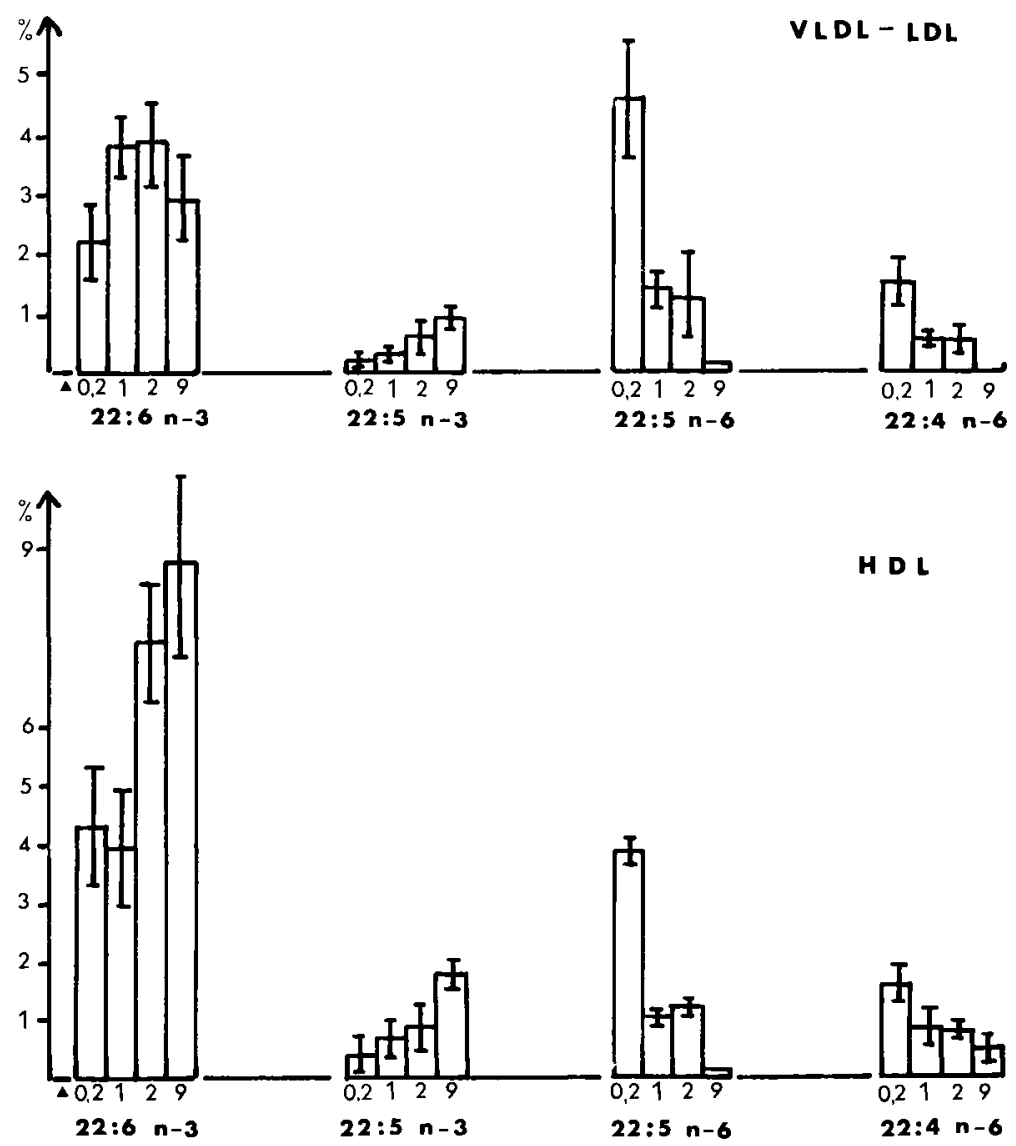

FIG. 1. - Evolution du taux des acides gras polyinsaturés de chaque série dans les phospholipides des lipoprotéines en fonction de l'apport en 18 : 3 n-3 dans le régime (0,2 \%-1 \%-2 \%-9 \%).

(A taux de $18: 3$ n-3 dans le régime maternel correspondant). 
le milieu synthétique de culture conduit à un profil en acides gras similaire à celui du tissu vivant du même âge (Bourre, 1983). Nous ne pouvons toutefois écarter I'hypothèse d'une captation directe des précurseurs $18: 2$ n-6 et $18: 3 n-3$, mais ce phénomène semble quantitativement peu important.

De plus, l'absence d'activité lipoprotéine lipase au niveau du cerveau renforce I'hypothèse d'une captation des acides gras par le cerveau à partir des phospholipides des lipoprotéines. Toutefois, les modalités de captation et de passage à travers la barrière hématoencéphalique sont encore inconnues.

$10^{\circ}$ Réunion du groupe Développement I.N.R.A., Rennes, 9-10 mai 1984.

\section{Références}

BOURRE J. M., POLLET S., PATURNEAU-JOUAS M., BAUMANN N., 1978. Fatty acid biosynthesis during brain development, 17-26. In GATT S., FREYSZ L., MANDEL P., Enzymes of lipid metabolism. Plenum Publ. Co, New York.

BOURRE J. M., 1983. Effect of polyunsatured fatty acids on fetal mouse brain cells in culture in a chemically defined medium. $J$. Neurochem., 11, 1234-1242.

COHEN P., BERNSOHN J., 1978. The in vivo incorporation of linolenic acid into neuronal and glial cells and myelin. J. Neurochem., 30, 661-663.

DHOPESHWARKAR G., SUBRAMANIAM C., MEAD J. F., 1971. Fatty acid uptake by the brain. Incorporation of $\left[1-{ }^{14} \mathrm{C}\right]$ linoleic acid into the adult rat brain. Biochim. biophys. Acta, 231, 814.

DHOPESHWARKAR G., SUBRAMANIAM C., MEAD J. F., 1971. Fatty acid uptake by the brain. Incorporation of $\left[1-{ }^{14} \mathrm{C}\right]$ linolenic acid into the adult rat brain. Biochim. biophys. Acta, 239, 162-167.

DHOPESHWARKAR G., SUBRAMANIAM C., 1976. Biosynthesis of polyunsaturated fatty acids in the developing brain. Metabolic transformation of intra cranially administrated $[1-14 \mathrm{C}]$ linolenic acid. Lipids, 11, 67-71.

SINCLAIR A. J., 1975. The incorporation of radioactive polyunsaturated fatty acids into the liver and brain of the developing rat. Lipids, 10, 175-184.

SINCLAIR A. J., CRAWFORD M. A., 1972. The accumulation of arachidonate and docosahexaenoate in the developing rat brain. J. Neurochem., 19, 1753-1758. 